Academic self-concept and achievement motivation among adolescent students in different learning environments: Does competence-support matter?

Stefan Kulakow

University of Greifswald

"This is an Accepted Manuscript of an article published by Elsevier in Learning and Motivation on 27/03/2020, available at https://doi.org/10.1016/j.lmot.2020.101632.”

(C) 2020. This manuscript version is made available under the CC-BY-NC-ND 4.0 license http://creativecommons.org/licenses/by-nc-nd/4.0/

\title{
Author Note
}

Stefan Kulakow, Department of Educational Science, Greifswald University. Correspondence concerning this article should be addressed to Stefan Kulakow, Department of Educational Science, Greifswald University, 17487 Greifswald, Germany. Phone: 00493834 4203734, E-mail: stefan.kulakow@uni-greifswald.de. 


\section{COMPETENCE-SUPPORT IN DIFFERENT LEARNING ENVIRONMENTS}

Abstract

The present study tests the following: a) whether perceived competence support functions as a mediator in the associations between academic self-concept and achievement motivation and $b$ ) how various learning environments shape these associations. A teacherdirected learning environment (TDL) and a student-centered approach, namely competencebased learning $(\mathrm{CBL})$, were contrasted using latent mean comparison and multi-group structural equation modeling with indirect effects. This study is based on a sample of German students in early and middle adolescence $\left(N=1,153 ; M_{\text {AgeTl }}=13.97, S D=1.37 ; M_{\text {AgeT2 }}=\right.$ $14.27, S D=1.25)$ in two waves $(\mathrm{T} 1=$ Autumn 2015 and $\mathrm{T} 2=$ Spring 2016). The results of the latent mean comparison indicate that students from schools with CBL perceive a higher level of academic self-concept compared to students from TDL environments. Moreover, multigroup structural equation modeling demonstrates that perceived competence support functions as a mediator in the association between academic self-concept and achievement motivation primarily for students from schools with CBL. Findings suggest that mostly students with a low level of academic self-concept benefit from CBL because this studentcentered learning environment reduces the association between academic self-concept and achievement motivation through a high level of perceived competence support.

Keywords: competence support, student-centered learning, teacher-directed learning, achievement motivation, self-concept, adolescence

Academic self-concept and achievement motivation among adolescent students in different learning environments: Does competence support matter?

\section{Introduction}

Adolescence is a particularly sensitive period in students' educational development. Students at an early age are expected to learn as effectively and efficiently as possible. These high expectations are paired with the pressures of highly competitive societies in which lifelong learning has become the key goal for a secure future. However, these demands are 


\section{COMPETENCE-SUPPORT IN DIFFERENT LEARNING ENVIRONMENTS}

associated with declines in adolescents' academic self-concept (Wigfield, Eccles, Mac Iver, Reuman, \& Midgley, 1991) and motivation (Anderman \& Midgley, 1997; Eccles, Wigfield, \& Schiefele, 1998; Harter, 1996; Watt, 2004; Zusho \& Pintrich, 2001). Accordingly, research has attempted to identify both the variables and learning environments that tend to compensate for these declines. Following stage-environment fit theory, a major contribution to these declines in motivation and self-concept in adolescence is attributed to a misfit of individual developmental needs and the provided educational environment (Eccles \& Midgley, 1989). Therefore, to effectively support adolescents in their scholastic education, it is imperative to examine learning environments and their characteristics that support the positive motivational development of adolescent students (Lazarides \& Raufelder, 2017).

An increasing number of schools have changed their instructional practices from teacher- to student-directed approaches to address the above-mentioned misfit effectively (OECD, 2017). Competence support thus plays a key role because perceived competence assumes a central function in students' performance, behavior, and motivation (Ryan \& Moller, 2017). One student-directed approach that is gaining growing attention among German schools is a learning environment based on competency matrices. This competencybased learning (CBL) environment uses competency matrices as a basis of instruction and thereby enables teachers to provide more in-depth and formative feedback on students' progress in their learning processes. However, less is known about the issue of whether students in CBL environments perceive higher levels of competence support, academic selfconcept, and achievement motivation compared to students in traditional teacher-directed learning environments. Furthermore, an understanding of the interplay of these particular variables in different learning environments is needed to identify best practices for preventing declines in achievement motivation.

Academic self-concept is a multidimensional construct that refers to an individual evaluation of personal cognitive abilities in academic achievement contexts (Harter, 1999, 


\section{COMPETENCE-SUPPORT IN DIFFERENT LEARNING ENVIRONMENTS}

2012). In the formation of academic self-concept, age is deemed to have a major contribution, with the period until middle adolescence being particularly vulnerable to declines (Marsh \& Hocevar, 1985; Wigfield et al., 1991). Two major influencing factors during this period are the transition from elementary to secondary schools and shifts in educational contexts (Wigfield \& Eccles, 2002; Wigfield et al., 2015). Between middle and late adolescence, academic self-concept then becomes more stable and less prone to changes (Marsh, 1989).

The theoretical framework of academic self-concept highlights the importance of the social environment (Marsh \& Martin, 2011; Marsh, Xu, \& Martin, 2012). In this domain, current research is focused on social contexts, such as the big-fish-little-pond effect, which play a key role in the formation of academic self-concept (Hoferichter, Lätsch, Lazarides, \& Raufelder, 2018; Marsh, 1984; Marsh \& Parker, 1984; Marsh, Trautwein, Lüdtke, Baumert, \& Köller, 2016; Stäbler, Dumont, Becker, \& Baumert, 2017). However, few studies have investigated the role of the learning environment itself, despite some promising results of certain intervention programs targeting academic self-concept (O'Mara, Marsh, Craven, \& Debus, 2006).

Numerous studies have indicated that academic self-concept is closely associated with academic performance (Marsh, Hau, Artelt, Baumert, \& Peschar, 2006) and motivational outcomes (Denissen, Zarrett, \& Eccles, 2007; Simpkins, Davis-Kean, \& Eccles, 2006), particularly achievement motivation (Wigfield et al., 2015), which conceptualizes domainunspecific competences such as persistence and effort, focus, and accuracy (Holz-Ebeling, 2010). Achievement motivation relates to a behavioral dimension of motivation (Eccles \&

Wigfield, 1995) insofar as it is distinct from cognitive dimensions, such as students' goals and goal orientations, and from affective dimensions, such as enjoyment of tasks (Eccles \& Wigfield, 2002). In classroom settings, this behavioral dimension is mostly observable when facing task-related difficulties (Lazarides \& Raufelder, 2017), such as individual persistence in pursuing learning activities (persistence and effort) and the intensity of students' 


\section{COMPETENCE-SUPPORT IN DIFFERENT LEARNING ENVIRONMENTS}

engagement (focus, accuracy) to organize learning processes and adapt to specific content and situations (Wigfield et al., 2015).

In spite of the reciprocal effect model, which states that self-concept and achievement constantly reinforce each other (Marsh, 1990; Marsh \& Craven, 2006; Marsh \& Martin, 2011), Garn and Shen (2014) demonstrated that the associations between academic selfconcept and motivational variables were rather mono- than bidirectional. In fact, self-concept predicted perceived competence support but not vice versa. They have thus hypothesized that self-concept might be more stable in nature and less prone to changes in contextual variables.

According to Deci and Ryan (1985), positive support of competence feelings is an integral determinant of students' motivation. Within self-determination theory, they define the need for competence as the feeling of effectiveness in the interaction with one's environment (Deci \& Ryan, 1985; Ryan \& Deci, 2000). Particularly in classrooms, this refers to the process of enabling students to experience opportunities and to express individual abilities and talents (Deci \& Ryan, 1980; Ryan \& Moller, 2005, 2017; White, 1959). This characteristic certainly distinguishes the need for competence from academic self-concept. The latter pertains to a rather individual cognitive evaluation of one's own capabilities (Harter, 1999, 2012), whereas the former denotes the intrinsic satisfaction of a person when effectively meeting the expectations of a challenge. Moreover, the support of academic selfconcept may require intensive interventions (O'Mara et al., 2006); by contrast, perceived competence support can be achieved through a teacher's more immediate means, such as providing differentiated learning activities that are appropriate to students' individual prerequisites (Niemiec \& Ryan, 2009).

The support of competence tends to result in increasing levels of motivation, academic performance, and well-being (Deci \& Ryan, 1985). Self-determination theory emphasizes the role of the context and its function in the satisfaction of one's needs (Deci \& Ryan, 2000a, 2000b), indicating that some environments are likely to be more need supportive than others 


\section{COMPETENCE-SUPPORT IN DIFFERENT LEARNING ENVIRONMENTS}

(Mouratidis, Vansteenkiste, Sideridis, \& Lens, 2011). Schools can certainly foster optimal conditions in which students' basic needs for competence can be satisfied, and teachers typically play a crucial role in this context (Katz \& Assor, 2006; Niemiec \& Ryan, 2009). On the one hand, those conditions refer to tasks and activities that enable students to extend their abilities. On the other hand, they refer to the type of feedback that students obtain. Deci and Ryan $(1985,2011)$ distinguish between controlling and informational elements. Especially in schools, providing feedback with reference to normative performance standards increases the presence of controlling elements (Ryan \& Moller, 2017). In contrast, informational feedback contains information about students' effectivity with higher levels of specificity and shorter temporal distances to the students' challenges (Ryan \& Moller, 2017).

Eccles and Midgley (1989) argue that, in particular, the transition from primary to secondary schools is a highly sensitive period in which discrepancies occur between students' individual needs and the contextual conditions; this is because the development into adolescence is coupled with disruptive changes in the educational setting. Moreover, Wang and Eccles (2012) suggest that the misfit increases throughout adolescence. These discrepancies are largely the results of ability grouping, summative assessment, lack of autonomy in one's own learning process, and whole-class instruction (Eccles \& Midgley, 1989). Eccles and Midgley (1989) stage-environment fit theory assumes that more facilitative educational environments can have positive effects. The idea of facilitative environments is also often taken up by self-determination theory (Ryan \& Deci, 2017) and respective empirical research (Lazarides \& Raufelder, 2017), indicating that the relations among variables may differ across different educational contexts. Instruction and differential treatment may especially have substantial effects on motivation and achievement (Eccles \& Roeser, 2011). Learning environments are consequently, and more importantly, necessary for achieving a congruence of individual needs and contextual conditions. 


\section{COMPETENCE-SUPPORT IN DIFFERENT LEARNING ENVIRONMENTS}

A student-centered learning environment has gained popularity among German schools in recent years. The aim of this learning environment is to attain a high degree of differentiated instruction and hence provide an initial position of learning that is most adaptive to students' prior knowledge. In contrast to a conventional teacher-directed learning (TDL) environment with whole-class instruction, the responsibility in the learning process is mainly shifted to the students (Schweder, Raufelder, Kulakow, \& Wulff, 2019). Students are enabled to coordinate learning processes with the help of an instructional instrument, namely a competency matrix (also often referred to as rubrics or competence grids). Competency matrices direct students with a task-based learning approach toward the attainment of educational standards, which have been developed for different subjects and age groups in Germany for the last decade (e.g., Sekretariat der Ständigen Konferenz der Kultusminister der Länder in der Bundesrepublik Deutschland, 2004). The matrices separate a subject's different goals on a vertical axis and differentiate them into competence levels on a horizontal axis (Stevens, Levi, \& Walvoord, 2013). The result is a complex matrix that allows for the determination of a specific individual competence level as the initial learning position. Based on this competence level, students can subsequently access learning material to advance in that competence field. As teachers are not responsible for instruction in this learning environment, they can focus on individual problems, offer continuous formative feedback, and generally provide a positive learning atmosphere.

Competency matrices particularly allow for consistent academic advancement. Students are given tasks and learning material, which follow Vygotsky's demand of structuring new content to the zone of proximal development (Vygotsky, 1981). The approximate fit of prior knowledge and new content should hence convey to students a continuous sense of capability and indirectly allow for constant success in actual performance-both factors contribute to an increase in the level of academic self-concept (O'Mara et al., 2006; Reeve \& Halusic, 2009). Students are similarly supposed to be provided 


\section{COMPETENCE-SUPPORT IN DIFFERENT LEARNING ENVIRONMENTS}

with a high degree of perceived competence support, as they obtain feedback on their competence development on a continuous basis. The mastery of a certain competence level should consequently address the specificity of feedback and provide prompt informational feedback on the student's progress.

Studies on competency matrices have primarily examined their potential in providing effective feedback and the validity of assessments based on those matrices (Jonsson \& Svingby, 2007). However, no studies have examined competence matrices as the predominant basis of instruction on a broad range of subjects and across grades in secondary education.

\subsection{Current Study and Hypotheses}

This study aims to fill the above-mentioned gap by examining whether substantial differences emerge in the interplay between academic self-concept, perceived competence support, and achievement motivation in students from both CBL and TDL environments, considering the potential age-specific effects between early and middle adolescence. By doing so, this study combines aspects of self-determination theory (Deci \& Ryan, 1985), stageenvironment fit theory (Eccles \& Midgley, 1989), and expectancy value theory (Eccles \& Wigfield, 1995) with the aim of deepening our understanding of CBL environments, in which motivational processes are fostered through perceived competence support independent of students' academic self-concept. Accordingly, this study particularly tests whether perceived competence support mediates the relationship between academic self-concept and achievement motivation. Following the method recommended by Baron and Kenny (1986), the current study fulfills all the preconditions of a mediation analysis. As previously mentioned, the existing empirical research has revealed that the predictor variable (academic self-concept) is significantly related to the outcome variable, namely, achievement motivation (Wigfield et al., 2015), whereas the mediating variable (perceived competence support) is significantly related to both the outcome (Deci \& Ryan, 1985; Ryan \& Deci, 2017) and the predictor variable, which is academic self-concept (Garn \& Shen, 2014). 


\section{COMPETENCE-SUPPORT IN DIFFERENT LEARNING ENVIRONMENTS}

The following hypotheses were tested based on the theoretical review. Hypothesis 1: Students from (a) TDL and (b) CBL environments differ in their perceptions of academic selfconcept, perceived competence support, and achievement motivation (persistence and effort, focus, and accuracy). Based on stage-environment fit theory (Eccles \& Midgley, 1989), it is assumed that $\mathrm{CBL}$ is a more flexible and facilitative environment, in which differentiated instruction is enabled through competence matrices. These competence matrices in turn allow teachers to focus more on the provision of formative feedback, resulting in higher scores of academic self-concept (Hypothesis 1a) and perceived competence support (Hypothesis 1b). As students with higher levels of academic self-concept and perceived competence support tend to demonstrate greater achievement motivation (Areepattamannil, 2012), we also assume higher values in persistence and effort, focus, and accuracy (Hypothesis 1c).

Perceived competence support may function as a mediator in the associations between academic self-concept and achievement motivation (Hypothesis 2). Therefore, potential learning environment and age-specific (Hypothesis 2a) differences could be expected (Eccles \& Midgley, 1989).

\section{Method}

\subsection{Participants and Procedure}

The data for this study were collected during the winter term (Time 1: T1) and summer term (Time 2: T2) of the German school year 2015-2016. The sample consists of 1,153 students aged $12-18$ from the $7^{\text {th }}$ to $10^{\text {th }}$ grades $\left(M_{\text {age }}=13.97 ; S D=1.37,49 \%\right.$ girls $)$ at $\mathrm{T} 1$ and $775\left(M_{\text {age }}=14.27, S D=1.25,49 \%\right.$ girls $)$ from the initial sample at T2 from six secondary schools in Germany. All six urban mixed- and lower-track schools included in this study were selected from the federal states of Mecklenburg-Western Pomerania, Berlin, Schleswig-Holstein, and North Rhine-Westphalia. Three of these schools $\left(N_{\text {classes }}=36\right)$ base their instruction on competence matrices and thus follow a student-centered learning approach 


\section{COMPETENCE-SUPPORT IN DIFFERENT LEARNING ENVIRONMENTS}

in their curricula. First, schools were researched online on the basis of available school profiles, with an emphasis on individualized learning with competence matrices. Second, schools were only incorporated into the pool of potential schools under the condition that all major subjects (German, Maths, and English) were taught exclusively on that basis. Since this approach is newly emerging, only three schools could be identified in which all $7^{\text {th }}$ to $10^{\text {th }}$ grade students have only experienced this learning environment in their secondary school days. Other potential schools have only just begun implementing it with the first classes. The other three $\left(N_{\text {classes }}=21\right)$ follow the traditional TDL approach with whole-class instruction as the main instructional practice. Because the identified CBL were exclusively low-track and mixed-track schools (“Oberschule"), the reference group also included these two school forms.

In Germany, school grades 7 and 8 ("Unterstufe") roughly correspond to early adolescence (ages 10-14) and grades 9 and 10 ("Mittelstufe") to middle adolescence (ages 15-17) (Lerner, 2002). To examine developmental differences in the interplay between the variables of interest (Eccles \& Midgley, 1989), we merged the aforementioned grades into the respective groups. We consequently formed the CBL $7 / 8$ group from students from the $7^{\text {th }}$ and $8^{\text {th }}$ grade $\left(N=478, M_{\text {age }}=13.04, S D=0.81,49 \%\right.$ girls $)$ and the CBL9/10 group from students from the $9^{\text {th }}$ and $10^{\text {th }}$ grade $\left(N=294, M_{\text {age }}=15.16 ; S D=0.87 ; 48 \%\right.$ girls $)$. Accordingly, the TDL sample comprised the TDL $7 / 8$ group $\left(N=211, M_{\text {age }}=13.35 ; S D=0.97 ; 55 \%\right.$ girls $)$ and the TDL9/10 group $\left(N=160, M_{\text {age }}=15.40 ; S D=1.05 ; 47 \%\right.$ girls $)$.

Data on ethnicity and socioeconomic status could not be gathered, because of German privacy laws, which prohibit asking somebody for information about another person, including ethnicity and parental income. After the educational authorities approved the conduct of the study, we informed schools, parents, and students about the purpose of the research, along with the anonymity of data collection and voluntary nature of participation. Two trained research assistants distributed the questionnaires to students and explained to 


\section{COMPETENCE-SUPPORT IN DIFFERENT LEARNING ENVIRONMENTS}

them the use of Likert scales. These research assistants were also present throughout the data collection process.

\subsection{Measures}

\subsubsection{Independent variable: Academic self-concept}

This measure was assessed by a subscale of Skalen zur Erfassung des schulischen Selbstkonzepts (Scales to assess school self-concept) by Schöne, Dickhäuser, Spinath, and Stiensmeier-Pelster (2012). The subscale, consisting of five items, demonstrated good reliability in the present sample (total sample: $\alpha=.84$, CBL7/8: $\alpha=.86$, CBL9/10: $\alpha=.82$, TDL7/8: $\alpha=.83$, TDL9/10: $\alpha=.83$ ). Items were measured with reference to normative performance criteria (Heckhausen \& Heckhausen, 2008) (e.g., "When I look at what we are supposed to know in school, I think that I am not intelligent / very intelligent") on a five-point Likert scale. This scale is based on self-concept theory (Marsh \& Martin, 2011).

\subsubsection{Mediator variable: Perceived competence support}

Perceived competence support was addressed using a subscale from Support of Basic Needs Scales for Adolescent Students by Müller and Thomas (2011). The subscale consisted of five items on a four-point Likert scale ranging from 1 (almost never) to 4 (almost always). It exhibited good reliability in the present sample (total sample: $\alpha=.87$, CBL7/8: $\alpha=.87$, CBL9/10: $\alpha=.88$, TDL7/8: $\alpha=.86$, TDL9/10: $\alpha=.89$ ). The subscale assessed students' perceived competence support from their teachers (e.g., "My teacher helps me when I am stuck with a problem") based on self-determination theory, which states that competence support is a central antecedent of motivation (Deci \& Ryan, 1985).

\subsubsection{Dependent variables: Achievement motivation}

Achievement motivation was addressed using the scales developed by Petermann and Petermann (2014), which associate achievement motivation - according to expectancy value theory - with its behavioral components (Eccles \& Wigfield, 1995; Petermann \& Petermann, 2014; Rheinberg, 2004). All three of the utilized subscales were measured on a four-point 


\section{COMPETENCE-SUPPORT IN DIFFERENT LEARNING ENVIRONMENTS}

Likert scale ranging from 1 (never) to 4 (often) with the help of four items each. The subscale focus measures the extent to which students can follow tasks assigned to them (e.g., "I am very attentive in class to understand everything"), and it achieved good reliability in the present sample (total sample: $\alpha=.81$, CBL7/8: $\alpha=.81$, CBL9/10: $\alpha=.81$, TDL7/8: $\alpha=.82$, TDL9/10: $\alpha=.81$ ). The subscale accuracy measures the extent to which students organize their work material to be effectively prepared for learning (e.g., "I sort my worksheets, so that I can find them easily"); it achieved good reliability in the present sample (total sample: $\alpha$ $=.82$, CBL7/8: $\alpha=.83$, CBL9/10: $\alpha=.84$, TDL7/8: $\alpha=.76$, TDL9/10: $\alpha=.80)$. Finally, the subscale persistence and effort assesses students' ability to work for a longer period of time and deal with more difficult tasks (e.g., "I am patient when I do my tasks"). It achieved good reliability in the present sample (total sample: $\alpha=.83$, CBL7/8: $\alpha=.83$, CBL9/10: $\alpha=.80$, TDL7/8: $\alpha=.86$, TDL9/10: $\alpha=.85)$.

\subsection{Statistical Analyses}

To test the hypotheses, we conducted latent mean comparison and multigroup structural equation modeling (MGSEM) with indirect effects using Mplus 8.1 (Muthén \& Muthén, 1998-2017). All the models were estimated with the maximum likelihood estimator with robust standard errors and Asparouhov's type-is-complex approach, which corrects standard error biases that emerge as a consequence of the hierarchical nature of our data (students nested in classes) (Asparouhov, 2005). Missing data were considered using the fullinformation-maximum-likelihood estimation.

Both latent mean comparison and MGSEM require the establishment of measurement invariance across all four groups. We subsequently performed confirmatory factor analyses (CFAs) on all latent constructs and continually added equality constraints to the models' parameters. First, all the models were estimated freely and separately (model 1: configural 


\section{COMPETENCE-SUPPORT IN DIFFERENT LEARNING ENVIRONMENTS}

measurement invariance). Second, all the groups were merged into one common model (model 2: factorial measurement invariance). Third, equality constraints were set on the factor loadings of all the latent constructs (model 3: weak factorial invariance). Finally, the equality constraints were extended to the factor intercepts (model 4: strong factorial invariance). In testing our hypotheses, reaching the level of at least partial strong factorial invariance was crucial for both latent mean comparison and MGSEM (Brown, 2015).

To test Hypothesis 2 concerning whether perceived competence support mediates the association between academic self-concept and achievement motivation (focus, accuracy, and persistence and effort) across all four groups, MGSEM with indirect effects was used. The estimates of the indirect effects were calculated using the delta method with symmetric confidence intervals (MacKinnon, 2008). We conceptualized three MGSEM approaches. The first, less restrictive MGSEM assumed measurement invariance (equal factor loadings or intercepts) but freely estimated regression and residual covariance coefficients. Second, a more restrictive model was estimated that assumed differences between both learning environments but equated regression and residual covariance coefficients between both age groups. Lastly, the third MGSEM assumed measurement invariance and additionally equated regression and covariance coefficients across all four groups.

The evaluation of the best fitting model was determined using the recommendations of $\mathrm{Hu}$ and Bentler (1999): $\chi 2$ test of model fit, root mean square error of approximation (RMSEA) with its respective confidence intervals, standardized root mean square residual (SRMR), comparative fit index (CFI), and Tucker-Lewis index (TLI). Model comparisons of the nested models, such as the invariance test and the test for group differences, were conducted through the $\chi^{2}$ difference test, which is based on log likelihood values and scaling correction factors, and through examining differences in CFI, TLI, RMSEA, and SRMR (Chen, 2007; Satorra \& Bentler, 2001). 


\section{COMPETENCE-SUPPORT IN DIFFERENT LEARNING ENVIRONMENTS}

\section{Results}

\subsection{Descriptive Statistics and Intercorrelations}

The descriptive statistics (means, standard deviations, range, skewness and kurtosis with their respective standard errors) along with the intercorrelations of all the latent variables for each group are presented in Table 1.

\section{Table 1}

Intercorrelations between the academic self-concept, competence support (T1) and focus, accuracy and persistence (T2) and their range, means, standard deviations, kurtosis and skewness for $7^{\text {th }} / 8^{\text {th }}$ and $9^{\text {th }} / 10^{\text {th }}$ grade students following CBL or TDL

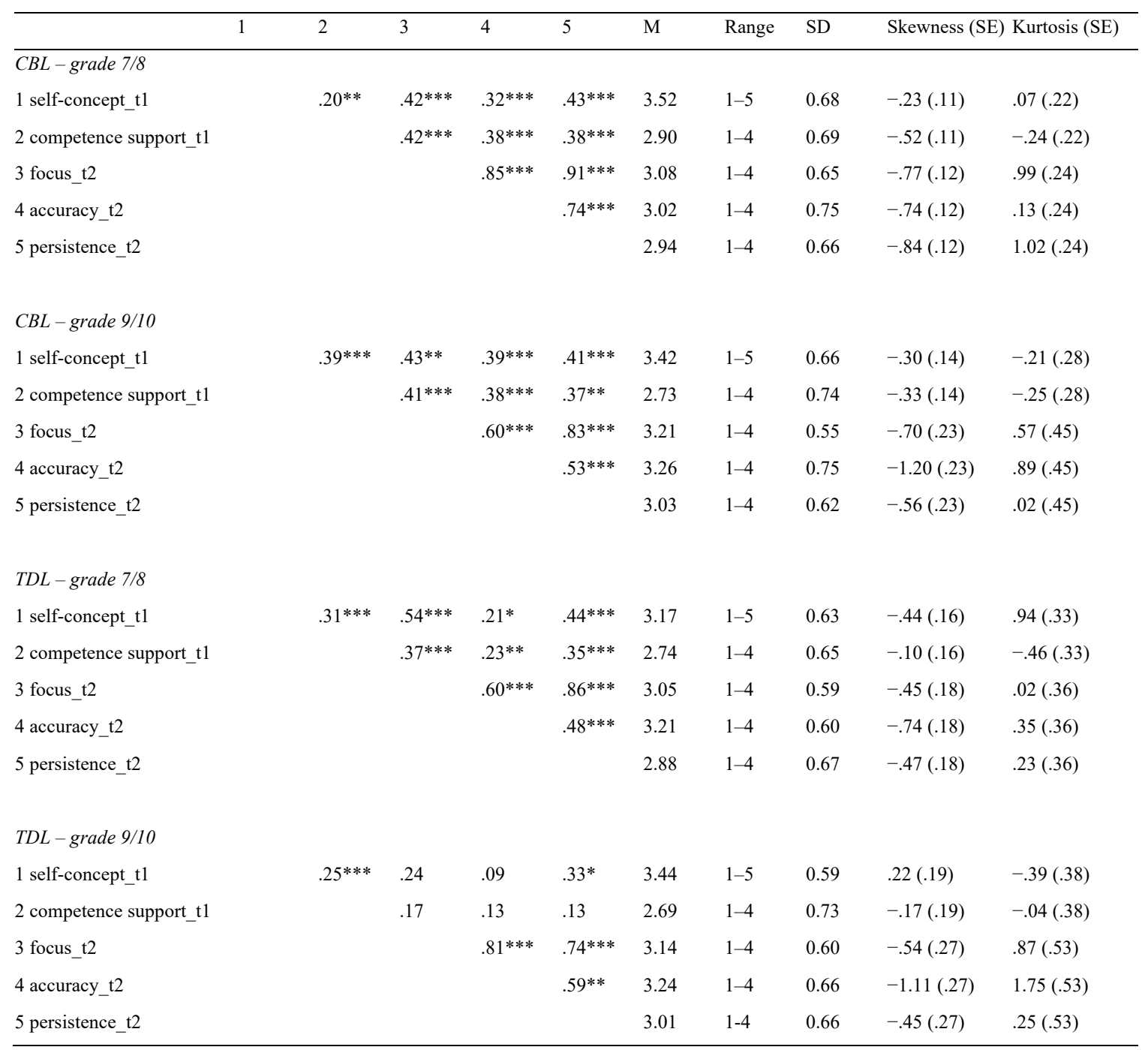




\section{COMPETENCE-SUPPORT IN DIFFERENT LEARNING ENVIRONMENTS}

Note. Self-concept_t $1=$ academic self-concept time 1, competence support_t $1=$ competence support time 1 , focus_t $2=$ focus time 2 , accuracy_t $2=$ accuracy time 2 , persistence_t $2=$ persistence and effort time $2{ }^{*} p<.05, * * p<.01, * * * p<.001$.

\subsection{Latent Mean Comparison}

To test Hypothesis 1, we conducted CFA on all the latent constructs to compare the latent means across all four groups and establish an initial measurement model for the mediation analysis (Hypothesis 2).

The CFA for measurement invariance confirmed the level of partial strong factorial invariance. The respective model fit indices and the results of the $\chi 2$ difference test are presented in Table 2 According to Brown (2015), a free estimation of certain factor parameters is justified and does not prohibit the comparison of latent means. Precisely, we freed one indicator of the accuracy scale in the CBL 7/8 group and one indicator of the academic self-concept scale in group TDL 7/8 and TDL 9/10. Thus, the preliminary analyses allowed for investigating both latent means and MGSEM.

\section{Table 2}

Model fit indices of the stepwise CFA procedure to proof measurement invariance

\begin{tabular}{lccccccccccc}
\hline Model & $\mathrm{df}$ & $\chi^{2}$ & $p$ & CFI & TLI & RMSEA & $90 \%$ CI & SRMR & $\Delta_{\chi}{ }^{2}$ & $\Delta \mathrm{df}$ & $p$ \\
\hline \multicolumn{2}{l}{ Invariance testing across groups } & & & & & & & & & \\
Model 1a & 199 & 352.671 & $<.001$ & .96 & .95 & .04 & $.03-.05$ & .04 & & & \\
Model 1b & 199 & 349.779 & $<.001$ & .92 & .91 & .05 & $.04-.06$ & .06 & & & \\
Model 1c & 199 & 262.206 & $<.001$ & .96 & .96 & .04 & $.02-.05$ & .05 & & & \\
Model 1d & 199 & 374.215 & $<.001$ & .89 & .87 & .07 & $.06-.09$ & .08 & & & \\
Model 2 & 796 & 1330.089 & $<.001$ & .94 & .93 & .05 & $.04-.05$ & .06 & & & \\
Model 3* & 847 & 1386.907 & $<.001$ & .94 & .94 & .05 & $.04-.05$ & .07 & 57.68 & 51 & .24 \\
Model 4a* & 898 & 1482.594 & $<.001$ & .94 & .94 & .05 & $.04-.05$ & .07 & 96.65 & 51 & $<.001$ \\
Model 4b** & 895 & 1451.652 & $<.001$ & .94 & .94 & .05 & $.04-.05$ & .07 & 63.90 & 48 & .06 \\
\hline
\end{tabular}

Note. Model 1a-d = measurement models for CBL 7/8, CBL 9/10, TDL 7/8, TDL 9/10 separately (configural invariance); Model $2=$ merged measurement model with all parameters 


\section{COMPETENCE-SUPPORT IN DIFFERENT LEARNING ENVIRONMENTS}

free (form invariance); Model 3 = equality of factor loadings (metric invariance); Model 4a = equality of factor intercepts (scalar invariance); Model $4 \mathrm{~b}=$ equality of several factor incepts (partial scalar invariance) *result of the $\chi 2$-difference test between the two subsequent models; **result of the $\chi 2$-difference test between Model $4 \mathrm{~b}$ (partial invariance) with Model 3 (metric invariance).

\subsubsection{Comparison of CBL vs. TDL}

Using students from CBL 7/8 as a reference group, students from TDL 7/8 exhibited significantly lower values concerning the academic self-concept at $\mathrm{T} 1(\beta=-0.55, p<.001)$, but students in TDL 7/8 reported greater values in accuracy at T2 (accuracy time $2: \beta=0.35$, $p<.05)$. However, both groups did not differ in perceived competence-support at $\mathrm{T} 1(\beta=-$ $0.25, p=.06)$, focus at T2 $(\beta=-0.02, p=.86)$, and persistence and effort at $\mathrm{T} 2(\beta=-0.06, p$

$=.62$ ). Results of the comparison between students from CBL 9/10 and students from TDL 9/10 indicated no significant differences between the groups: perceived competence-support at T1 $(\beta=-0.04, p=.82)$, academic self-concept at T1 $(\beta=-0.07, p=.60)$, accuracy at T2 ( $\beta$ $=0.01, p=.13)$, focus at $\mathrm{T} 2(\beta=0.10, p=.67)$, and persistence and effort at $\mathrm{T} 2(\beta=-0.06, p$ $=.80)$ did not differ significantly.

\subsubsection{Comparison of latent means across time}

The developmental perspective within CBL demonstrated that the middle adolescent students in CBL 9/10 reported significantly less perceived competence-support at T1 $(\beta=$ $0.25, p<.05)$ but more accuracy at T2 $(\beta=0.29, p<.05)$. Academic self-concept at T1 $(\beta=-$ $0.16, p=.10)$, focus at $\mathrm{T} 2(\beta=0.23, p=.14)$, and persistence and effort at $\mathrm{T} 2(\beta=0.18, p$ $=.28$ ) did not differ between the two groups.

In the TDL environment, middle adolescent students reported significantly higher values of academic self-concept at $\mathrm{T} 1(\beta=.46, p<.001)$. All other latent constructs did not change over time: perceived competence-support at T1 $(\beta=-.09, p=.64)$, accuracy at T2 ( $\beta$ 


\section{COMPETENCE-SUPPORT IN DIFFERENT LEARNING ENVIRONMENTS}

$=.05, p=.82)$, focus at $\mathrm{T} 2(\beta=.15, p=.44)$, and persistence and effort at $\mathrm{T} 2(\beta=.17, p$ $=.33)$.

\subsection{Multigroup Structural Equation Modeling}

Based on the intercorrelations in Table 1, the interplay of the variables of interest was assumed to differ across all four groups. Thus, we developed our conceptualized model. In this model, perceived competence-support mediates the association between academic selfconcept (independent variable) and achievement motivation (dependent variables of focus, accuracy, and persistence and effort).

First, we produced the less-restrictive model (model 1), which included the invariance assumptions of CFA, but freely estimated regression and residual covariance coefficients. Therefore, the direct effects from the academic self-concept on perceived competence-support and on the achievement motivation variables (focus, accuracy, and persistence and effort) were added, implying the hypothesis that group differences in the interplay exist. Moreover, the residuals of the dependent variables were allowed to covary with each other. This model produced a good fit: $\chi 2(898)=1482.593, p\left(\chi^{2}\right)<.001$, CFI $=.94$, TLI $=.94$, RMSEA $(90 \%$ $\mathrm{CI})=.05[.04, .05], \mathrm{SRMR}=.07$.

Second, a more restrictive model (model 2) was computed that assumed differences in terms of the learning environment, but did not assume differences in terms of age.

Consequently, regression and residual covariance coefficients were equated between the age groups within both learning environments. This model also produced good fit indices $\left(\chi 2(918)=1518.387, p\left(\chi^{2}\right)<.001, \mathrm{CFI}=.94, \mathrm{TLI}=.94, \mathrm{RMSEA}(90 \% \mathrm{CI})=.05[.04, .05]\right.$, $\operatorname{SRMR}=.09)$

Last, a model with more restrictions (model 3) was tested, which additionally placed equality constraints on all the direct effects and residual covariance coefficients across all four groups, implying the non-existence of group differences, both in terms of the learning 


\section{COMPETENCE-SUPPORT IN DIFFERENT LEARNING ENVIRONMENTS}

environment and the age of the students. This model produced a good fit as well: $\chi 2(928)=$ $1537.416, p\left(\chi^{2}\right)<.001, \mathrm{CFI}=.93, \mathrm{TLI}=.93$, RMSEA $(90 \% \mathrm{CI})=.05[.04, .05], \mathrm{SRMR}=.10$.

Finally, the models were compared in a step-wise procedure. The comparisons of model 1 and model $2\left(\Delta \chi^{2}=36.27, \Delta \mathrm{df}=20 ; p<.001 ; \Delta \mathrm{CFI}=.00 ; \Delta \mathrm{TLI}=.00 ; \Delta \mathrm{RMSEA}\right.$ $=.00 ; \Delta \mathrm{SRMR}=.02)$, and the comparisons of model 2 and model $3\left(\Delta \chi^{2}=18.94, \Delta \mathrm{df}=10 ; p\right.$ $<.001 ; \Delta \mathrm{CFI}=.01 ; \Delta \mathrm{TLI}=.01 ; \Delta \mathrm{RMSEA}=.00 ; \Delta \mathrm{SRMR}=.01)$ indicated a slight, but significant decreases in model fit when introducing the equality constraints. Consequently, significant differences in the patterns between the variables of interest among the four groups were assumed based on the final least restrictive model (model 1).

\subsubsection{Patterns for CBL in early adolescence.}

Figure 1 illustrates the final model for the CBL 7/8 group.

\section{Figure 1}

Final model for the $7^{\text {th }} / 8^{\text {th }}$ grade students following $C B L$

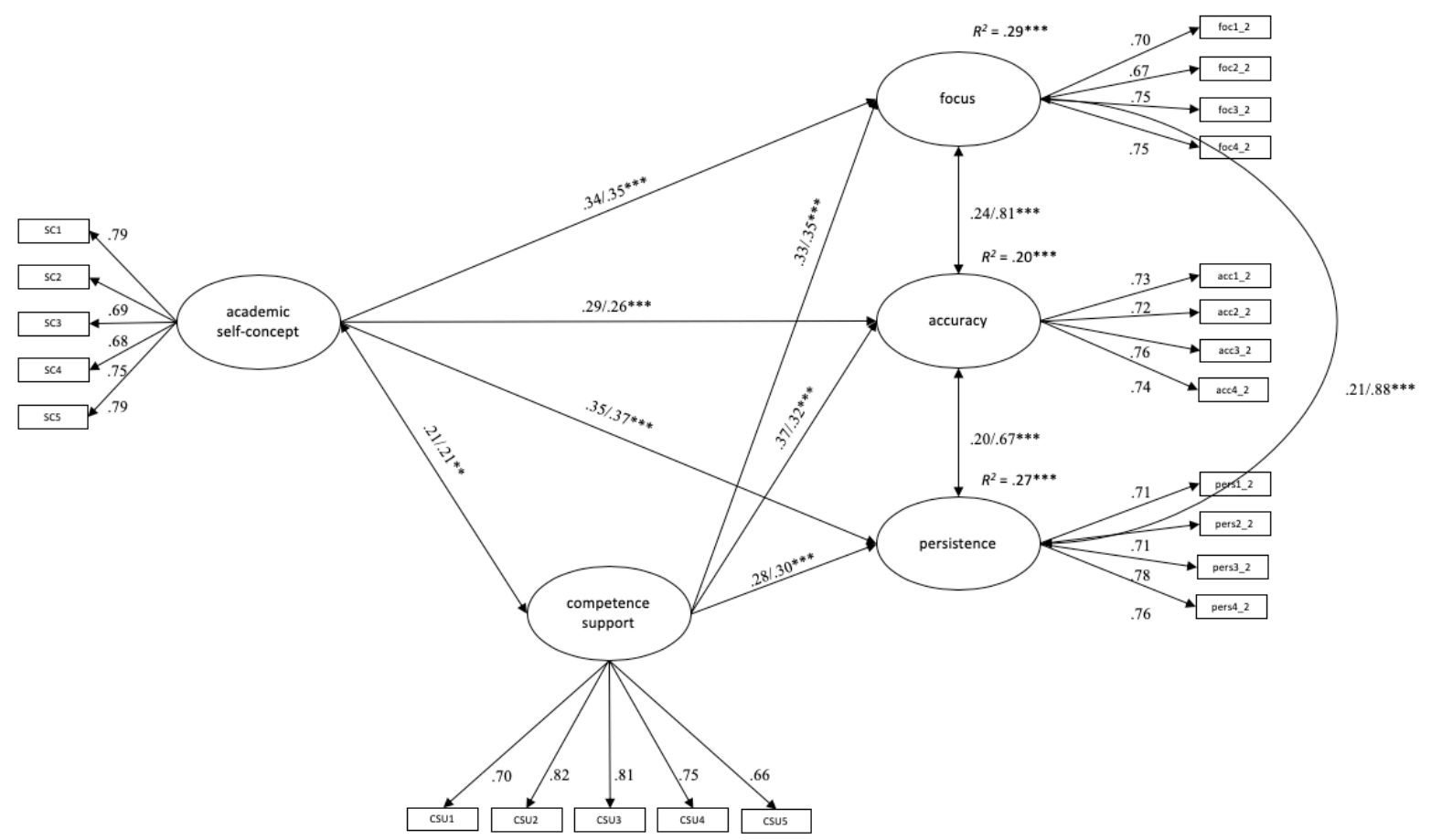




\section{COMPETENCE-SUPPORT IN DIFFERENT LEARNING ENVIRONMENTS}

Note. $* \mathrm{p}<.05, * * \mathrm{p}<.01, * * * \mathrm{p}<.001$; in contrast to this depiction, the calculation of the confidence intervals suggest insignificant indirect effects.

Academic self-concept at T1 is significantly associated with perceived competencesupport at $\mathrm{T} 1(B=0.21, \beta=0.21, S E=0.06, p<.01)$, with focus at T2 $(B=0.34, \beta=0.35, S E$ $=0.05, p<.001)$, with accuracy at T2 $(B=0.29, \beta=0.26, S E=0.06, p<.001)$, and with persistence and effort at T2 $(B=0.35, \beta=0.37, S E=0.05, p<.001)$. Moreover, perceived competence-support at T1 predicted focus at T2 $(B=0.33, \beta=0.35, S E=0.05, p<.001)$, accuracy at $\mathrm{T} 2(B=0.37, \beta=0.32, S E=0.06, p<.001)$, and persistence and effort at T2 $(B=$ $0.28, \beta=0.30, S E=0.04, p<.001)$.

All the associations between academic self-concept and the three achievement motivation variables were found to be positively mediated by perceived competence-support. Perceived competence-support at $\mathrm{T} 1$ partially mediated the association between academic self-concept at T1 and focus at T2 $(B=0.07, \beta=0.07, S E=0.02,95 \% C I[0.03,0.11])$, and accuracy at $\mathrm{T} 2(B=0.08, \beta=0.07, S E=0.03,95 \% C I[0.02,0.13])$, and persistence and effort at T2 $(B=0.06, \beta=0.06, S E=.02,95 \% C I[0.02,0.09])$.

The residual covariance of focus at T2 and accuracy at T2 was positively associated ( $r$ $=.81, p<.001)$, as were the residual covariances between focus at T2 and persistence and effort at T2 $(r=.88, p<.001)$, and accuracy at T2 and persistence and effort at T2 $(r=.67, p$ $<.001)$. Overall, this model accounted for $29.2 \%$ of the variation of focus at T2 $\left(R^{2}=.292, p\right.$ $<.001), 20.3 \%$ of accuracy at T2 $\left(R^{2}=.203, p<.001\right)$, and $26.9 \%$ of persistence and effort at $\mathrm{T} 2\left(R^{2}=.269, p<.001\right)$.

\subsubsection{Patterns for CBL in middle adolescence.}

Figure 2 depicts the final model for the CBL 9/10 group. 


\section{COMPETENCE-SUPPORT IN DIFFERENT LEARNING ENVIRONMENTS}

\section{Figure 2}

Final model for the $9^{\text {th }} / 10^{\text {th }}$ grade students following $C B L$

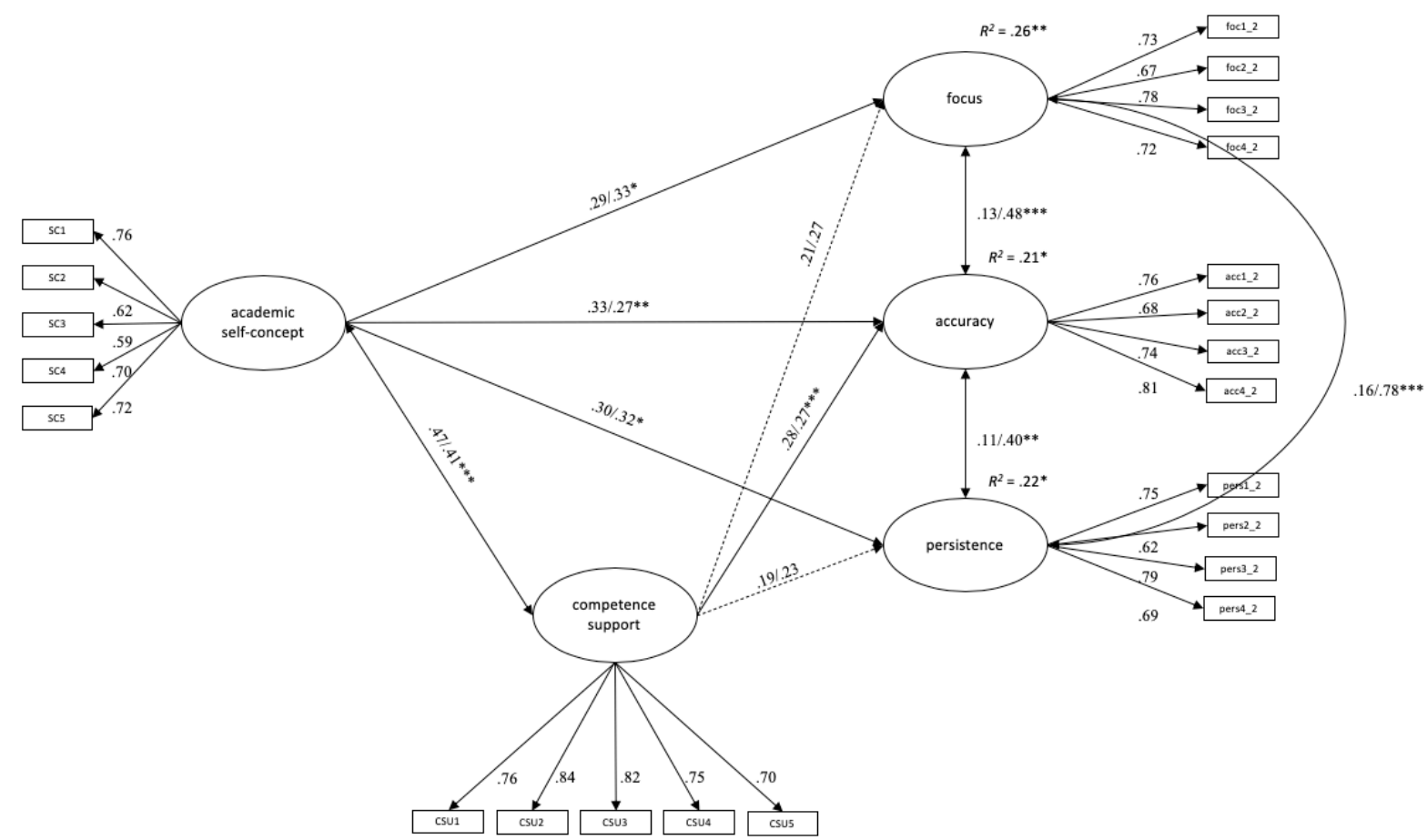

Note. $* \mathrm{p}<.05, * * \mathrm{p}<.01, * * * \mathrm{p}<.001$; in contrast to this depiction, the calculation of the confidence intervals suggest insignificant indirect effects.

In the CBL 9/10 group, we have identified five significant direct effects: academic self-concept at T1 is associated with perceived competence-support at T1 $(B=0.47, \beta=0.41$, $S E=0.10, p<.001)$, with focus at T2 $(B=0.29, \beta=0.33, S E=0.12, p<.05)$, with accuracy at T2 $(B=0.33, \beta=0.27, S E=0.10, p<.01)$, and with persistence and effort at T2 $(B=0.30$, $\beta=0.32, S E=0.12, p<.05)$. Moreover, perceived competence-support at T1 is positively associated with accuracy at $\mathrm{T} 2(B=0.28, \beta=0.27, S E=0.08, p<.001)$.

In the middle adolescent CBL 9/10 group, perceived competence-support at T1 positively mediated the association between academic self-concept at $\mathrm{T} 1$ and accuracy at $\mathrm{T} 2$ $(B=0.13, \beta=0.11, S E=0.05,95 \% C I[0.04,0.23])$. However, the competence support did not mediate the association between academic self-concept at T1 and focus at T2 $(B=0.10, \beta$ 


\section{COMPETENCE-SUPPORT IN DIFFERENT LEARNING ENVIRONMENTS}

$=0.11, S E=0.07,95 \% C I[-0.03-0.23])$ and between academic self-concept at T1 and persistence and effort at T2 $(B=0.09, \beta=0.10, S E=0.05,95 \% C I[-0.01-0.19])$.

The residuals of all three dependent variables were positively associated: focus at T2 with accuracy at T2 $(r=.48, p<.001)$, focus at T2 with persistence and effort at T2 $(r=.78$, $p<.001)$, and accuracy at T2 with persistence and effort at T2 $(r=.40, p<.01)$.

Overall, this model explained $25.6 \%$ of the variation of focus at T2 $\left(R^{2}=.256, p<\right.$ $01), 20.6 \%$ of accuracy at T2 $\left(R^{2}=.206, p<.05\right)$, and $22.2 \%$ of persistence and effort at T2 $\left(R^{2}=.222, p<.05\right)$

\subsubsection{Patterns for TDL in early adolescence.}

Figure 3 presents the final model for the TDL $7 / 8$ group.

\section{Figure 3}

Final model for the $7^{\text {th }} / 8^{\text {th }}$ grade students following TDL

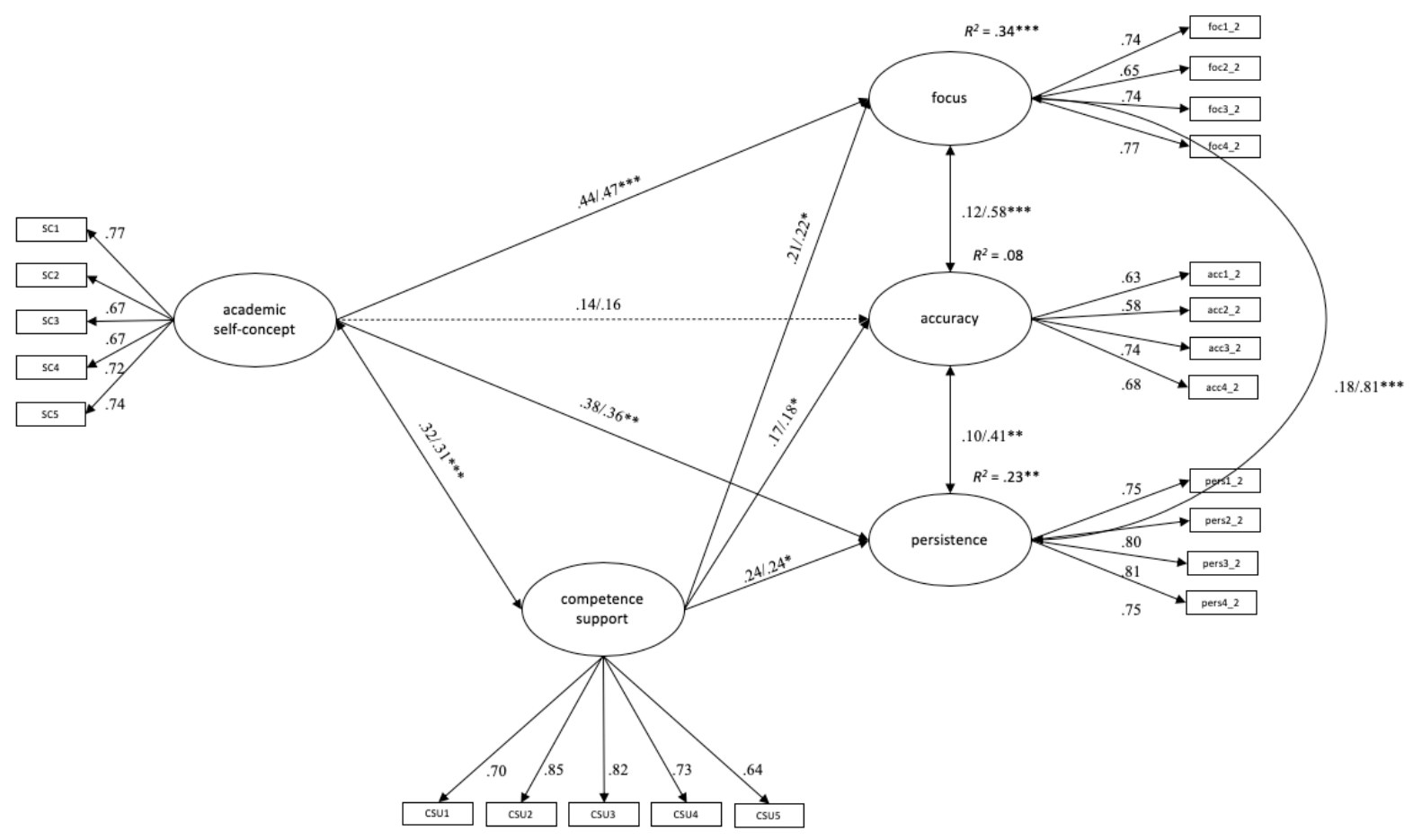

Note. $* \mathrm{p}<.05, * * \mathrm{p}<.01, * * * \mathrm{p}<.001$. 


\section{COMPETENCE-SUPPORT IN DIFFERENT LEARNING ENVIRONMENTS}

In the TDL 7/8 group, six of the seven direct effects were found to be significantly associated. Academic self-concept at T1 was positively associated with perceived competence-support at T1 $(B=0.32, \beta=0.31, S E=0.09, p<.001)$, with focus at $\mathrm{T} 2(B=$ $0.44, \beta=0.47, S E=0.08, p<.001)$, and with persistence and effort at T2 $(B=0.38, \beta=0.36$, $S E=0.12, p<.01)$. Moreover, perceived competence-support at T1 was associated with focus at T2 $(B=0.21, \beta=0.22, S E=0.09, p<.05)$, with accuracy at T2 $(B=0.17, \beta=0.18, S E=$ $0.08, p<.05)$, and with persistence and effort at $\mathrm{T} 2(B=0.24, \beta=0.24, S E=0.10, p<.05)$.

No significant indirect effect could be identified for the TDL $7 / 8$ group. Perceived competence-support at $\mathrm{T} 1 \mathrm{did}$ not mediate the association between academic self-concept at $\mathrm{T} 1$ and focus at $\mathrm{T} 2(B=0.07, \beta=0.07, S E=0.03,95 \% C I[-0.001,0.13])$, and accuracy at T2 $(B=0.05, \beta=0.06, S E=0.03,95 \% C I[-0.001,0.11])$, and persistence and effort at T2 $(B=$ $0.08, \beta=0.07, S E=0.04,95 \% C I[-0.001,0.16])$.

The residuals of all the dependent variables were positively associated in the TDL 7/8 group: focus at T2 with accuracy at $\mathrm{T} 2(r=.58, p<.001)$, focus at T2 with persistence and effort at T2 $(r=.81, p<.001)$, and accuracy at T2 with persistence and effort at T2 $(r=.41, p$ $<.001)$

The final model of TDL 7/8 explained $33.8 \%$ of variation of focus at T2 $\left(R^{2}=.338, p\right.$ $<.001)$ and $24.3 \%$ of persistence and effort at T2 $\left(R^{2}=.243, p<.01\right)$. The coefficient of determination was insignificant for accuracy at T2 $\left(R^{2}=.075, p=.08\right)$.

\subsubsection{Patterns for TDL in middle adolescence.}

Figure 4 illustrates the final model for the TDL 9/10 group.

\section{Figure 4}

Final model for the $9^{\text {th }} / 10^{\text {th }}$ grade students following TDL 


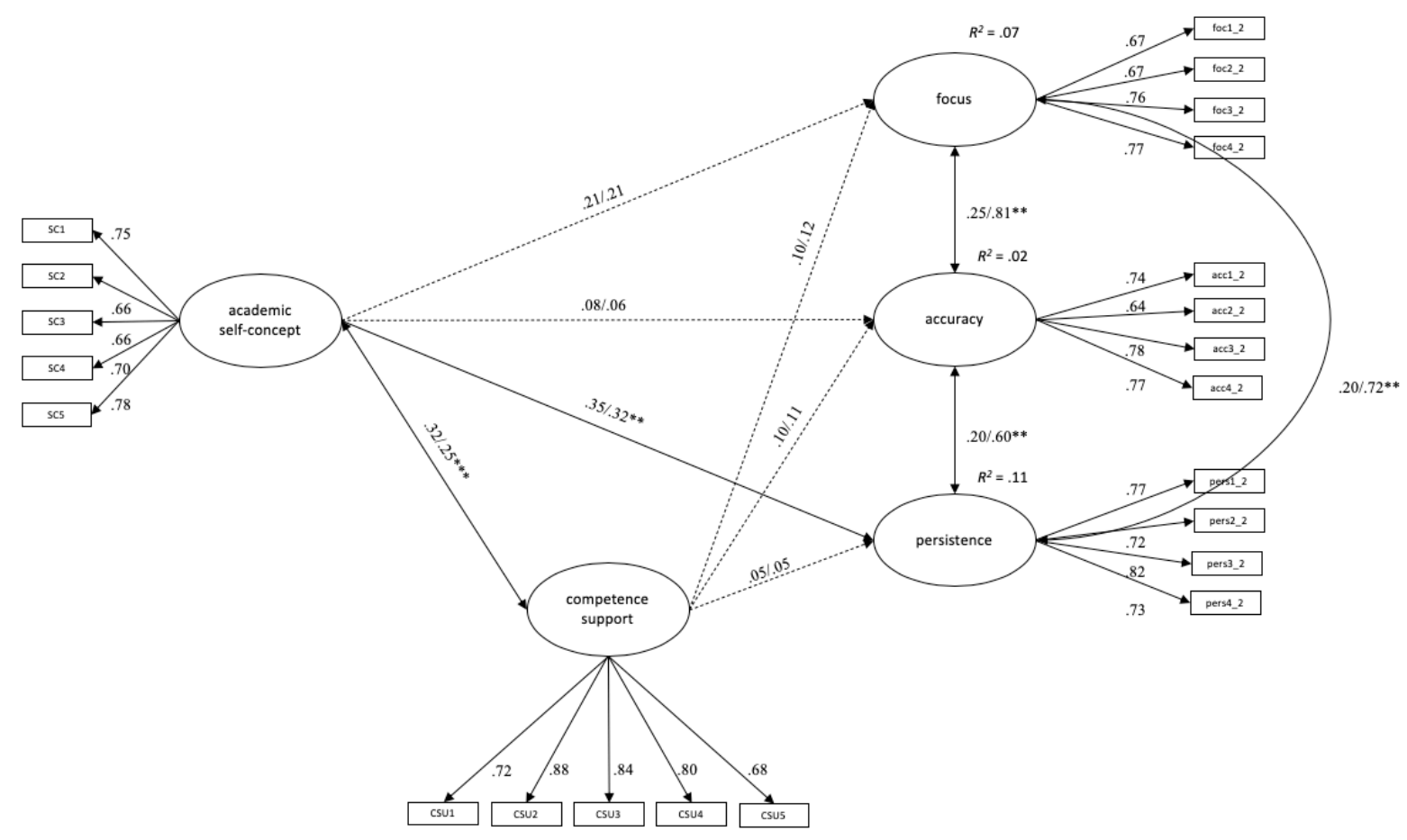

Note. $* \mathrm{p}<.05, * * \mathrm{p}<.01, * * * \mathrm{p}<.001$.

In the TDL9/10 group, two of the seven effects were found to be significantly associated: academic self-concept at $\mathrm{T} 1$ predicted perceived competence support at $\mathrm{T} 1(B=$ $0.32, \beta=0.25, S E=0.08, p<.001)$ and persistence and effort at $\mathrm{T} 2(B=0.35, \beta=0.32, S E=$ $0.13, p<.01)$

Significant indirect effects for the TDL9/10 group were lacking, and perceived competence support at $\mathrm{T} 1$ consequently did not mediate the association between academic self-concept at T1 and focus at T2 $(B=0.03, \beta=0.03, S E=0.02,95 \% C I[-0.02,0.08])$, accuracy at $\mathrm{T} 2(B=0.03, \beta=0.03, S E=0.03,95 \% C I[-0.03,0.10])$, and persistence and effort at $\mathrm{T} 2(B=0.01, \beta=0.01, S E=0.03,95 \% C I[-0.05,0.08])$.

In the CBL9/10 group, the residuals of all dependent variables were significantly associated at T2: focus and accuracy $(r=.81, p<.001)$, focus and persistence and effort $(r$ $=.72, p<.001)$, accuracy and persistence and effort $(r=.60, p<.001)$. 


\section{COMPETENCE-SUPPORT IN DIFFERENT LEARNING ENVIRONMENTS}

This final model did not explain any variation in the dependent variables: focus at T2 $\left(R^{2}=.070, p=.50\right)$, accuracy at T2 $\left(R^{2}=.019, p=.52\right)$, and persistence and effort at T2 $\left(R^{2}\right.$ $=.112, p=.23)$.

\section{Discussion}

This study investigated the role of perceived competence support in the association between academic self-concept and achievement motivation among early and middle adolescent students in different learning environments (CBL vs. TDL). It specifically examined whether students in early adolescence and middle adolescence from classes following CBL vs. TDL differ in the variables' mean values and whether perceived competence support equally functions as a mediator between academic self-concept and achievement motivation for each group.

Hypothesis 1a was only partially confirmed: students following CBL reported significantly greater values in academic self-concept than students from TDL environments. This result aligns well with O'Mara et al. (2006) meta-analysis, which indicates that intervention characteristics, such as individual counseling and feedback, have significant effect sizes on academic self-concept. The reduced responsibility of teachers to instruct the students creates additional capacities for them to provide individual feedback. In addition, competence matrices enable students to continuously experience progress in their learning processes and to have this progress visibly reflected to them, which might even enrich the personal feedback of teachers. Furthermore, the effects of social comparison on academic self-concept (Hoferichter et al., 2018) can be reduced because of students' ability to simultaneously work on different competence fields. However, this difference did not replicate at T2. In summary, this supports the notion that age might be an important factor for self-concept interventions (O'Mara et al., 2006).

Contrary to Hypothesis $1 b$, students from CBL vs. TDL environments did not significantly differ in their perceived competence support, neither in early adolescent nor in 


\section{COMPETENCE-SUPPORT IN DIFFERENT LEARNING ENVIRONMENTS}

middle adolescent students. This result might have occurred because of the scale that was used in this study: the perceived competence support scale solely focuses on the provision of competence by the person of the teacher (e.g., "My teacher helps me when I am stuck with a problem") (Müller \& Thomas, 2011) rather than by the entity of the learning environment. Considering a study on the importance of social relations in scholastic education (Raufelder, Jagenow, Drury, \& Hoferichter, 2013), we determine that teachers are only partly perceived as motivational resources, whereas the need for competence may also be satisfied by various other influences. This aspect may well apply to the TDL environment in which teachers assume a central role in the classroom; by contrast, teachers in CBL classrooms have a relatively distal role in the instructional process, and the students themselves enhance their competence independently.

The results of achievement motivation contradicted Hypothesis 1c. While a) persistence and effort and b) focus did not differ between the groups, a mean difference in accuracy at T1 was identified in favor of the TDL environment. Nevertheless, this difference might more strongly reflect classroom demands within the two learning environments.

Teacher-directed learning environments are more dependent on accuracy as teachers cannot properly adapt to previous content if students inadequately prepare their material. By contrast, the necessary accuracy in CBL environments might be more flexible because of individual needs and demands.

With regard to Hypothesis 2a, significant differences occurred in the associations between the academic self-concept, perceived competence support, and achievement motivation (persistence and effort, accuracy, and focus) of early and middle adolescent students from both learning environments (CBL vs. TDL). Specifically, for early adolescent CBL students, perceived competence support partially mediated all the associations between academic self-concept and achievement motivation (persistence and effort, accuracy, and focus). For middle adolescent students in CBL environments, only the association between 


\section{COMPETENCE-SUPPORT IN DIFFERENT LEARNING ENVIRONMENTS}

academic self-concept and accuracy was partially mediated by perceived competence support. However, while the confidence intervals indicated insignificant indirect effects for the middle adolescent group, parameter estimates were in fact higher in this group which may indicate insufficient statistical power to detect the significance of the effect. As perceived competence support reduces the associations (partial mediation) between academic self-concept and achievement motivation, students' motivation can be better fostered through high perceived competence support in CBL independent of their academic self-concept, compared to students in TDL. In other words, perceived competence support in class can protect achievement motivation. An open question, however, remains whether the mediator actually loses relevance in middle adolescence or whether it is only the power that failed to detect the effects. This may contribute to a more proper understanding of stage-environment fit (Eccles \& Midgley, 1989), namely whether appropriate adjustments in learning environments are necessary throughout adolescence.

On the contrary, the statistically significant mediating effects of perceived competence support between academic self-concept and achievement motivation could not be identified for students in TDL environments, neither for early nor middle adolescent students. However, similarly to the middle adolescent CBL group, the early adolescent TDL sample exhibited comparable parameter estimates to the early and middle adolescent CBL sample. However, in the TDL case, sample size might have led to the rejection of the alternative hypothesis. Achievement motivation of students in TDL seems to be more strongly associated with relatively stable factors such as academic self-concept, and external factors such as perceived competence support cannot dissolve this relationship. This inflexible relationship might be because achievement motivation in such a learning environment could be much more strongly dependent on the teachers and their central position in this classroom context. This aspect is particularly problematic as it indicates that students' achievement motivation is rather attached to a person who will eventually disappear from their academic life. This dependency 


\section{COMPETENCE-SUPPORT IN DIFFERENT LEARNING ENVIRONMENTS}

relates to raising and educating students without the premise of becoming independent in their learning processes. Furthermore, the expected differences of stage-environment fit theory (Eccles \& Midgley, 1989) between TDL7/8 and TDL9/10 were present, even though they were negative. Although TDL7/8 lacked indirect effects, academic self-concept and competence support significantly contributed to achievement motivation in terms of direct effects. The majority of these effects was not present in the middle adolescent TDL9/10 group. This lack of effects is linked particularly to the predictor, namely, perceived competence support. Ryan and Moller (2017) consider perceived competence support to be an insufficient condition for achievement motivation. Instead, perceived competence support depends on the presence of autonomy. However, TDL environments frequently fail to provide autonomy support (Reeve, 2009; Reeve, Jang, Carrell, Jeon, \& Barch, 2004). In contrast, the development of students from early adolescence to middle adolescence is accompanied by an increasing need for autonomy (Eccles et al., 1991). The gap between the needs' satisfaction of the environment and the actual needs consequently broadens. This assumption could also be made, if we consider that the lack of indirect effects in the TDL7/8 sample was only caused by insufficient statistical power. In that case, it could be argued that the associations between academic self-concept, perceived competence-support, and achievement motivation are not moderated by the learning environment. However and in support of stage-environment fit theory (Eccles \& Midgley, 1989), distinctive differences are evident if we consider the middle adolescent TDL group.

The coefficients of determination are alarming for the TDL9/10 group, although they must be considered carefully because of the relatively small subsample. The final model for this group could not explain any significant variation in the dependent variables, indicating that neither academic self-concept nor perceived competence support play an important role in students' achievement motivation, contrary to predominant educational theory. We can consequently assume that restrictive and controlling learning environments may even 


\section{COMPETENCE-SUPPORT IN DIFFERENT LEARNING ENVIRONMENTS}

suppress the relations among the variables. Ryan and Deci (2017) argue that schools often tend to fail to capitalize on establishing learning environments that support the diversity of their students, such as their interests and capacities. Instead, "grades, awards, and social comparisons are commonplace" (p. 351).

\subsection{Theoretical Implications}

These results align well with both the theoretical background within both selfdetermination theory (Ryan \& Deci, 2000) and stage-environment fit theory (Eccles \& Midgley, 1989). Based on self-determination theory, Ryan and Moller (2017) refer to the need for competence as an essential but insufficient condition for motivation. According to the theory, this condition may be attributable not only to the provision of autonomy as a basic need within the learning environment but also to the environment itself (Ryan \& Deci, 2017), which provides either optimal conditions for satisfying a person's needs or conditions that thwart them. To utilize the needs, learning activities should be adaptive to varying levels of challenge (Ryan \& Moller, 2017). If the learning environment is somewhat controlling und externally regulated, then competence need satisfaction becomes rather redundant, and minimal performance outputs are to be expected (Taylor et al., 2014). Comparable results were also indicated by Raufelder, Regner, Drury, and Eid (2015), who found considerable inter-individual differences in the role of perceived competence support depending on the socio-motivational type of students. Self-determination theory argues that the satisfaction of the need for competence depends to a large degree on teaching style and teacher feedback (Niemiec \& Ryan, 2009), similarly to academic self-concept (Usher, 2016).

In summary, TDL is assumed to be a relatively controlling environment in which perceived competence support is incapable of dissolving the relationship between academic self-concept and achievement motivation, particularly in middle adolescence. This assumption provides further evidence for the dependency of perceived competence support on contextual conditions. In contrast, students following the CBL approach are widely 


\section{COMPETENCE-SUPPORT IN DIFFERENT LEARNING ENVIRONMENTS}

autonomous in engaging in learning activities with the help of competence matrices. This flexibility in the context conditions enables the integration of perceived competence support to foster achievement motivation.

Drawing on stage-environment fit theory (Eccles \& Midgley, 1989), we assume that the CBL environment is more favorable than the conventional TDL environment. According to the theory, educational contexts may facilitate or thwart the motivational development of students. The learning environment in CBL enables more flexible associations between the variables of interest and possibly easier intervention possibilities. Furthermore, the possible sources of a better context fit might lie in less teacher control coupled with more opportunities for decision-making and autonomy, better teacher-student relationships, and less social comparison and competition (Roeser, Eccles, \& Sameroff, 1998; Wang, 2009). To a certain extent, these factors are addressed in the CBL environment, and if Reeve and Halusic (2009's) recommendations for autonomous teaching practices are considered, then this learning environment's incorporation of a number of those factors without depending on the teacher becomes apparent.

\subsection{Practical Implications}

From an instructional viewpoint, students in CBL face an environment in which they have the opportunity to learn at their own pace and expand their skills and prior knowledge. In traditional classroom contexts (TDL), however, teachers prefer relatively homogeneous learning groups because such structures help them to address their students' instructional needs (Chorzempa \& Graham, 2006). In the past decade, awareness has grown not only in the divergent instructional needs but also in other variable motivational requirements that significantly affect learning. Furthermore, learning environments should be more adaptive to these needs and provide a broader range of possible arrangements than pure whole-class instruction. In addition to highlighting the instructional viewpoint, the CBL environment enables teachers to individually focus on students. This focus refers to individual help if 


\section{COMPETENCE-SUPPORT IN DIFFERENT LEARNING ENVIRONMENTS}

students are unable to cope with the instruction based on the competence matrices or with task difficulty. Moreover, whole-class instruction in TDL frequently denotes that high-ability students are restrained from progressing in certain competence fields or vice versa; at the same time, low-ability students are left behind because they either need more time to deal with certain contents or lack the prior knowledge to appropriately connect it with new skills and knowledge. The major concern with perceived competence support in TDL classrooms might lie in the fact that students cannot suitably address the feedback issued by teachers, as these teachers will continue with instruction to meet the needs of other students who will otherwise become bored. The responsibility of catching up to the instructional level of the class is thus placed outside of the classroom. In contrast, students in CBL classrooms do not depend on their teachers' instruction and are able to effectively address prior feedback within their time at school. In that sense, CBL represents a learning environment that unties the dependency on the teacher and shifts the responsibility for achievement motivation and learning to the student. In such autonomy in learning, the support of competence bolsters achievement motivation.

\subsection{Limitations, Strengths, and Future Directions}

This study has some limitations that must be addressed. First, it used solely questionnaires and therefore self-report data. However, our singular focus was on investigating the internal states of participants rather than their actual performance behavior. Moreover, the study participants were adolescent students, and in contrast to younger children, adolescent students do not tend to have difficulty in expressing their internal states. We consequently believe in the appropriateness of self-report data. Second, the four age groups were not equally distributed; and significant effects may also be caused by greater statistical power. This poses a problem as many of the indirect effects barely failed to reach the significance level of .05, which mostly affected the CBL9/10 which even showed higher parameter estimates in contrast to the significant estimates of the CBL7/8 group. 


\section{COMPETENCE-SUPPORT IN DIFFERENT LEARNING ENVIRONMENTS}

Therefore, replication studies are warranted to confirm or refute these findings. Third, the issue of partial invariance is problematic. Brown (2015) criticizes this procedure as it is a post-hoc procedure without theoretical rationales. On the other hand, however, the large sample size of this study has sufficient power to detect even marginal differences in these parameter estimates. An attempt was made to minimize the potential for misleading results of the latent mean comparisons by freeing only the minimum number of factor intercepts. Moreover, future studies might test self-concept as a potential mediator in the relationship between perceived competence support and achievement motivation, as both predictor and mediator were assessed at the same timepoint in our study. Therefore, the regressions in the SEM are assumed to be conceptual relations rather than causal relations. Furthermore, we could not include demographic control variables such as socioeconomic status and ethnicity, which are prohibited by the educational administration resulting from German privacy laws. Finally, generalizability is limited to a certain degree because of the non-random sample of the CBL group, in which no high-tracking and schools from rural areas were incorporated. This selectiveness also leads to a restricted random sample of the TDL group, which then had to exclude rural and high-tracking schools as well to achieve comparability. If the CBL learning environment continues to gain popularity in the school system, future studies should aim to incorporate schools with those features to achieve representativeness of the sample.

This study also offers several strengths. First, it compares students' academic selfconcept, achievement motivation, and perceived competence support in different instructional learning environments. It specifically considers and identifies the essential differences between students from schools with traditional teacher-directed learning (TDL) environments and those from a newly emerging student-centered learning environment (CBL), which empirically supports stage-environment fit theory. Future longitudinal studies are required to confirm these findings and investigate how different learning environments contribute to motivational development in scholastic education. This is particularly necessary as the 


\section{COMPETENCE-SUPPORT IN DIFFERENT LEARNING ENVIRONMENTS}

indirect effects were rather small. Because of the theoretical similarities between self-concept and perceived competence-support, an additional empirically driven analysis was conducted in which both constructs were specified as predictors. The results of that analysis can be found in the online supplement (Appendix A).

Moreover, the present study was conducted on the basis of stage-environment-fit theory (Eccles \& Midgley, 1989). With that theoretical background and the subsequent division of the sample in two age groups, multilevel analyses were not feasible anymore. Even with manifest measurement and manifest aggregation approach (Lüdtke, Marsh, Robitzsch, \& Trautwein, 2011), which would introduce other bias to the model, the number of L2 units (e.g., classes) and L3 (e.g., schools) was too small. Future studies should focus on sampling a high number of classes and schools to capture the hierarchical nature of the data and perform multilevel analyses. These analyses could further increase the reliability and validity of the findings and verify/ falsify the findings of the present study.

Furthermore, the study reveals that perceived competence support in CBL environments can decrease the influence of academic self-concept on students' motivation. This factor is particularly important for the enhancement of students with a low level of academic self-concept and who are more often at risk for a downward tendency of their motivation during adolescence (Bakadorova \& Raufelder, 2016; Hay, Ashman, \& van Kraayenoord, 1998). 


\section{COMPETENCE-SUPPORT IN DIFFERENT LEARNING ENVIRONMENTS}

\section{References}

Anderman, E. M., \& Midgley, C. (1997). Changes in achievement goal orientations, perceived academic competence, and grades across the transition to middle-level schools. Contemporary Educational Psychology, 22(3), 269-298. doi:10.1006/ceps.1996.0926

Areepattamannil, S. (2012). Mediational role of academic motivation in the association between school self-concept and school achievement among Indian adolescents in Canada and India. Social Psychology of Education, 15(3), 367-386. doi:10.1007/s11218-012-9187-1

Asparouhov, T. (2005). Sampling weights in latent variable modeling. Structural Equation Modeling: A Multidisciplinary Journal, 12(3), 411-434. doi:10.1207/s15328007sem1203_4

Bakadorova, O., \& Raufelder, D. (2016). Do socio-motivational relationships predict achievement motivation in adolescents with high and low school self-concepts? The Journal of Educational Research, 109(3), 219-231. doi:10.1080/00220671.2014.942031

Baron, R. M., \& Kenny, D. A. (1986). The moderator-mediator variable distinction in social psychological research: Conceptual, strategic, and statistical considerations. Journal of Personality and Social Psychology, 51(6), 1173-1182. doi:10.1037//00223514.51.6.1173

Brown, T. A. (2015). Confirmatory factor analysis for applied research (2nd ed.). New York: Guilford Press.

Chen, F. F. (2007). Sensitivity of Goodness of Fit Indexes to Lack of Measurement Invariance. Structural Equation Modeling: A Multidisciplinary Journal, 14(3), 464504. doi:10.1080/10705510701301834 


\section{COMPETENCE-SUPPORT IN DIFFERENT LEARNING ENVIRONMENTS}

Chorzempa, B. F., \& Graham, S. (2006). Primary-grade teachers' use of within-class ability grouping in reading. Journal of Educational Psychology, 98(3), 529-541. doi:10.1037/0022-0663.98.3.529

Deci, E. L., \& Ryan, R. M. (1980). The empirical exploration of intrinsic motivational processes. In L. Berkowitz (Ed.), Advances in experimental social psychology (Vol. 13, pp. 39-80). New York, NY: Academic Press.

Deci, E. L., \& Ryan, R. M. (1985). Intrinsic motivation and self-determination in human behavior. New York, NY: Springer.

Deci, E. L., \& Ryan, R. M. (2000a). Handbook of self-determination research. Rochester, NY: University of Rochester Press.

Deci, E. L., \& Ryan, R. M. (2000b). The "what" and "why" of goal pursuits: Human needs and the self-determination of behavior. Psychological Inquiry, 11(4), 227-268. doi:10.1207/s15327965pli1104_01

Denissen, J. J., Zarrett, N. R., \& Eccles, J. S. (2007). I like to do it, I'm able, and I know I am: longitudinal couplings between domain-specific achievement, self-concept, and interest. Child Dev, 78(2), 430-447. doi:10.1111/j.1467-8624.2007.01007.x

Eccles, J. S., Buchanan, C. M., Flanagan, C., Fuligni, A., Midgley, C., \& Yee, D. (1991). Control Versus Autonomy During Early Adolescence. Journal of Social Issues, 47(4), 53-68. doi:10.1111/j.1540-4560.1991.tb01834.x

Eccles, J. S., \& Midgley, C. (1989). Stage-environment fit: Developmentally appropriate classrooms for young adolescents. In C. Ames \& R. Ames (Eds.), Research on motivation in education (Vol. 3, pp. 139-186). San Diego, CA: Academic Press.

Eccles, J. S., \& Roeser, R. W. (2011). Schools as Developmental Contexts During Adolescence. Journal of Research on Adolescence, 21(1), 225-241. doi:10.1111/j.1532-7795.2010.00725.x 


\section{COMPETENCE-SUPPORT IN DIFFERENT LEARNING ENVIRONMENTS}

Eccles, J. S., \& Wigfield, A. (1995). In the Mind of the Actor: The Structure of Adolescents' Achievement Task Values and Expectancy-Related Beliefs. Personality and Social Psychology Bulletin, 21(3), 215-225. doi:10.1177/0146167295213003

Eccles, J. S., \& Wigfield, A. (2002). Motivational beliefs, values, and goals. Annual Review of Psychology, 53, 109-132. doi:10.1146/annurev.psych.53.100901.135153

Eccles, J. S., Wigfield, A., \& Schiefele, U. (1998). Motivation to succeed. In W. Damon \& N. Eisenberg (Eds.), Handbook of child psychology (5 ed., Vol. 3, pp. 1017-1095). New York, NY: Wiley.

Garn, A., \& Shen, B. (2014). Physical self-concept and basic psychological needs in exercise: Are there reciprocal effects? International Journal of Sport and Exercise Psychology, 13(2), 169-181. doi:10.1080/1612197x.2014.940994

Harter, S. (1996). Teacher and classmate influences on scholastic motivation, self-esteem, and level of voice in adolescents. In J. Juvonen \& K. R. Wentzel (Eds.), Social motivation - Understanding children's school adjustment (pp. 11-42). Cambridge, NY: Cambridge University Press.

Harter, S. (1999). The construction of the self: A developmental perspective. New York, NY: Guilford Press.

Harter, S. (2012). The construction of the self: Developmental and sociocultural foundations (2nd ed.). New York, NY: Guilford Press.

Hay, I., Ashman, A. F., \& van Kraayenoord, C. E. (1998). Educational characteristics of students with high or low self-concept. Psychology in the Schools, 35(4), 391-400. doi:10.1002/(sici)1520-6807(199810)35:4<391::aid-pits10>3.0.co;2-\#

Heckhausen, J., \& Heckhausen, H. (2008). Motivation and action. New York, NY: Cambridge University Press. 


\section{COMPETENCE-SUPPORT IN DIFFERENT LEARNING ENVIRONMENTS}

Hoferichter, F., Lätsch, A., Lazarides, R., \& Raufelder, D. (2018). The Big-Fish-Little-Pond Effect on the four facets of academic self-concept. Frontiers in Psychology, 9, 1247. doi:10.3389/fpsyg.2018.01247

Holz-Ebeling, F. (2010). Arbeitsverhalten und Arbeitsprobleme [Work behavior and problems]. In D. H. Rost (Ed.), Handwörterbuch Pädagogische Psychologie (4th rev. ed., pp. 29-38). Weinheim, Germany: Beltz.

Hu, L. T., \& Bentler, P. M. (1999). Cutoff criteria for fit indexes in covariance structure analysis: Conventional criteria versus new alternatives. Structural Equation Modeling: A Multidisciplinary Journal, 6(1), 1-55. doi:10.1080/10705519909540118

Jonsson, A., \& Svingby, G. (2007). The use of scoring rubrics: Reliability, validity and educational consequences. Educational Research Review, 2(2), 130-144. doi:10.1016/j.edurev.2007.05.002

Katz, I., \& Assor, A. (2006). When Choice Motivates and When It Does Not. Educational Psychology Review, 19(4), 429-442. doi:10.1007/s10648-006-9027-y

Lazarides, R., \& Raufelder, D. (2017). Longitudinal effects of student-perceived classroom support on motivation - A latent change model. Frontiers in Psychology, 8, 417. doi:10.3389/fpsyg.2017.00417

Lüdtke, O., Marsh, H. W., Robitzsch, A., \& Trautwein, U. (2011). A 2 x 2 taxonomy of multilevel latent contextual models: accuracy-bias trade-offs in full and partial error correction models. Psychol Methods, 16(4), 444-467. doi:10.1037/a0024376

MacKinnon, D. P. (2008). Introduction to statistical mediation analysis. New York, NY: Lawrence Erlbaum Associates.

Marsh, H. W. (1984). Self-concept: The application of a frame of reference model to explain paradoxical results. Australian Journal of Education, 28(2), 165-181. doi:10.1177/000494418402800207 


\section{COMPETENCE-SUPPORT IN DIFFERENT LEARNING ENVIRONMENTS}

Marsh, H. W. (1990). Causal ordering of academic self-concept and academic achievement: A multiwave, longitudinal panel analysis. Journal of Educational Psychology, 82(4), 646-656. doi:10.1037/0022-0663.82.4.646

Marsh, H. W., \& Craven, R. G. (2006). Reciprocal effects of self-concept and performance from a multidimensional perspective: Beyond seductive pleasure and unidimensional perspectives. Perspect Psychol Sci, 1(2), 133-163. doi:10.1111/j.17456916.2006.00010.x

Marsh, H. W., Hau, K.-T., Artelt, C., Baumert, J., \& Peschar, J. L. (2006). OECD's Brief SelfReport Measure of Educational Psychology's Most Useful Affective Constructs: Cross-Cultural, Psychometric Comparisons Across 25 Countries. International Journal of Testing, 6(4), 311-360. doi:10.1207/s15327574ijt0604_1

Marsh, H. W., \& Hocevar, D. (1985). Application of confirmatory factor analysis to the study of self-concept: First- and higher order factor models and their invariance across groups. Psychological Bulletin, 97(3), 562-582. doi:10.1037/0033-2909.97.3.562

Marsh, H. W., \& Martin, A. J. (2011). Academic self-concept and academic achievement: relations and causal ordering. British Journal Educational Psychology, 81(Pt 1), 5977. doi:10.1348/000709910X503501

Marsh, H. W., \& Parker, J. W. (1984). Determinants of student self-concept: Is it better to be a relatively large fish in a small pond even if you don't learn to swim as well? Journal of Personality and Social Psychology, 47(1), 213-231. doi:10.1037/00223514.47.1.213

Marsh, H. W., Trautwein, U., Lüdtke, O., Baumert, J., \& Köller, O. (2016). The Big-FishLittle-Pond Effect: Persistent negative effects of selective high schools on self-concept after graduation. American Educational Research Journal, 44(3), 631-669. doi:10.3102/0002831207306728 


\section{COMPETENCE-SUPPORT IN DIFFERENT LEARNING ENVIRONMENTS}

Marsh, H. W., Xu, M., \& Martin, A. J. (2012). Self-concept: A synergy of theory, method, and application. In K. Harris, S. Graham, \& T. Urdan (Eds.), APA Educational Psychology Handbook (pp. 427-458). Washington, DC: American Psychological Association.

Mouratidis, A. A., Vansteenkiste, M., Sideridis, G., \& Lens, W. (2011). Vitality and interestenjoyment as a function of class-to-class variation in need-supportive teaching and pupils' autonomous motivation. Journal of Educational Psychology, 103(2), 353-366. doi:10.1037/a0022773

Müller, F. H., \& Thomas, A. E. (2011). Skalen zur wahrgenommenen Basic Needs Unterstützung von Schüler/innen [Support of basic needs scales for adolescent students]. Retrieved from Klagenfurt, Austria: https://ius.aau.at/wpcontent/uploads/2016/01/Schuelerfragebogen_BN_U.pdf

Muthén, L. K., \& Muthén, B. O. (1998-2017). Mplus user's guide (8th ed.). Los Angeles, CA: Muthén \& Muthén.

Niemiec, C. P., \& Ryan, R. M. (2009). Autonomy, competence, and relatedness in the classroom: Applying self-determination theory to educational practice. Theory and Research in Education, 7(2), 133-144. doi:10.1177/1477878509104318

O'Mara, A. J., Marsh, H. W., Craven, R. G., \& Debus, R. L. (2006). Do Self-Concept Interventions Make a Difference? A Synergistic Blend of Construct Validation and Meta-Analysis. Educational Psychologist, 41(3), 181-206. doi:10.1207/s15326985ep4103_4

OECD. (2017). The OECD handbook for innovative learning environments. Paris: OECD Publishing.

Petermann, U., \& Petermann, F. (2014). Schülereinschätzliste für Sozial- und Lernverhalten [Students' assessment-list for social and learning habits]. Göttingen, Germany: Hogrefe. 


\section{COMPETENCE-SUPPORT IN DIFFERENT LEARNING ENVIRONMENTS}

Raufelder, D., Jagenow, D., Drury, K., \& Hoferichter, F. (2013). Social relationships and motivation in secondary school: Four different motivation types. Learning and Individual Differences, 24, 89-95. doi:10.1016/j.lindif.2012.12.002

Raufelder, D., Regner, N., Drury, K., \& Eid, M. (2015). Does self-determination predict the school engagement of four different motivation types in adolescence? Educational Psychology, 36(7), 1242-1263. doi:10.1080/01443410.2015.1008405

Reeve, J. (2009). Why teachers adopt a controlling motivating style toward students and how they can become more autonomy supportive. Educational Psychologist, 44(3), 159175. doi:10.1080/00461520903028990

Reeve, J., \& Halusic, M. (2009). How K-12 teachers can put self-determination theory principles into practice. School Field, 7(2), 145-154. doi:10.1177/1477878509104319

Reeve, J., Jang, H., Carrell, D., Jeon, S., \& Barch, J. (2004). Enhancing students' engagement by increasing teachers' autonomy support. Motivation and Emotion, 28(2), 147-169. doi:10.1023/B:MOEM.0000032312.95499.6f

Rheinberg, F. (2004). Motivationsdiagnostik [Diagnostics of Motivation]. Göttingen, Germany: Hogrefe.

Roeser, R. W., Eccles, J. S., \& Sameroff, A. J. (1998). Academic and emotional functioning in early adolescence: Longitudinal relations, patterns, and prediction by experience in middle school. Development and Psychopathology, 10(2), 321-352. doi:10.1017/s0954579498001631

Ryan, R. M., \& Deci, E. L. (2000). Self-determination theory and the facilitation of intrinsic motivation, social development, and well-being. American Psychologist, 55(1), 68-78. doi:10.1037//0003-066x.55.1.68

Ryan, R. M., \& Deci, E. L. (2017). Self-determination theory: Basic psychological needs in motivation, development, and wellness. New York, NY: Guilford. 


\section{COMPETENCE-SUPPORT IN DIFFERENT LEARNING ENVIRONMENTS}

Ryan, R. M., \& Moller, A. C. (2005). The concept of competence: A starting place for understanding intrinsic motivation and self-determined extrinsic motivation. In A. E. Elliot \& C. S. Dweck (Eds.), Handbook of competence and motivation (pp. 579-597). New York, NY: Guilford Press.

Ryan, R. M., \& Moller, A. C. (2017). Competence as central, but not sufficient, for high quality motivation: A self-determination theory perspective. In A. E. Elliot, C. S. Dweck, \& D. S. Yeager (Eds.), Handbook of competence and motivation: Theory and application (2nd ed., pp. 214-231). New York, NY: Guilford Press.

Satorra, A., \& Bentler, P. M. (2001). A scaled difference chi-square test statistic for moment structure analysis. Psychometrika, 66(4), 507-514. doi:10.1007/bf02296192

Schöne, C., Dickhäuser, O., Spinath, B., \& Stiensmeier-Pelster, J. (2012). SESSKO: Skalen zur Erfassung des schulischen Selbstkonzepts. Manual [Scales to assess school selfconcept] (2nd rev. ed.). Göttingen, Germany: Hogrefe.

Sekretariat der Ständigen Konferenz der Kultusminister der Länder in der Bundesrepublik Deutschland, (KMK). (2004). Bildungsstandards: Erläuterungen zur Konzeption und Entwicklung [Educational standards of the conference of ministers of education and cultural affairs]. München, Germany: Luchterhand.

Simpkins, S. D., Davis-Kean, P. E., \& Eccles, J. S. (2006). Math and science motivation: A longitudinal examination of the links between choices and beliefs. Dev Psychol, 42(1), 70-83. doi:10.1037/0012-1649.42.1.70

Stäbler, F., Dumont, H., Becker, M., \& Baumert, J. (2017). What happens to the fish's achievement in a little pond? A simultaneous analysis of class-average achievement effects on achievement and academic self-concept. Journal of Educational Psychology, 109(2), 191-207. doi:10.1037/edu0000135 


\section{COMPETENCE-SUPPORT IN DIFFERENT LEARNING ENVIRONMENTS}

Stevens, D. D., Levi, A. J., \& Walvoord, B. E. (2013). Introduction to rubrics: An assessment tool to save grading time, convey effective feedback, and promote student learning (2nd ed.). Herndon, VA: Stylus Publishing.

Taylor, G., Jungert, T., Mageau, G. A., Schattke, K., Dedic, H., Rosenfield, S., \& Koestner, R. (2014). A self-determination theory approach to predicting school achievement over time: the unique role of intrinsic motivation. Contemporary Educational Psychology, 39(4), 342-358. doi:10.1016/j.cedpsych.2014.08.002

Usher, E. L. (2016). Personal capability beliefs. In L. Corno \& E. M. Anderman (Eds.), Handbook of educational psychology (3rd ed., pp. 146-159). New York, NY: Routledge.

Vygotsky, L. S. (1981). Mind in society. The development of higher psychological processes. Cambridge, MA: Harvard University Press.

Wang, M.-T. (2009). School climate support for behavioral and psychological adjustment: Testing the mediating effect of social competence. School Psychology Quarterly, 24(4), 240-251. doi:10.1037/a0017999

Wang, M.-T., \& Eccles, J. S. (2012). Adolescent behavioral, emotional, and cognitive engagement trajectories in school and their differential relations to educational success. Journal of Research on Adolescence, 22(1), 31-39. doi:10.1111/j.15327795.2011.00753.x

Watt, H. M. (2004). Development of adolescents' self-perceptions, values, and task perceptions according to gender and domain in 7th- through 11th-grade Australian students. Child Development, 75(5), 1556-1574. doi:10.1111/j.14678624.2004.00757.x

White, R. W. (1959). Motivation reconsidered: The concept of competence. Psychological Review, 66(5), 297-333. doi:10.1037/h0040934 


\section{COMPETENCE-SUPPORT IN DIFFERENT LEARNING ENVIRONMENTS}

Wigfield, A., Eccles, J. S., Fredricks, J. A., Simpkins, S., Roeser, R. W., \& Schiefele, U. (2015). Development of achievement motivation and engagement. In M. E. Lamb (Ed.), Handbook of child psychology and developmental science (7th ed., Vol. 3, pp. 657-700). Hoboken, NJ: John Wiley \& Sons.

Wigfield, A., Eccles, J. S., Mac Iver, D., Reuman, D. A., \& Midgley, C. (1991). Transitions during early adolescence: Changes in children's domain-specific self-perceptions and general self-esteem across the transition to junior high school. Developmental Psychology, 27(4), 552-565. doi:10.1037/0012-1649.27.4.552

Zusho, A., \& Pintrich, P. R. (2001). Motivation in the second decade of life. In T. Urdan \& F. Pajares (Eds.), Adolescence and education (pp. 163-200). Greenwich, CT: Information Age Publishing. 


\section{COMPETENCE-SUPPORT IN DIFFERENT LEARNING ENVIRONMENTS}

\section{Appendix A}

As the indirect effects were weak, an alternative model was conceptualized in which perceived competence support and academic self-concept predicted achievement motivation (model 1). This model produced a good fit: $\chi^{2}(898)=1482.594, p\left(\chi^{2}\right)<.001$, CFI $=.94$, TLI $=.94, \operatorname{RMSEA}(90 \% \mathrm{CI})=.05[.04, .05], \mathrm{SRMR}=.07$. Second, a more restrictive model (model 2) was computed that assumed differences in terms of the learning environment, but did not assume differences in terms of age. Consequently, regression and residual covariance coefficients were equated between the age groups within both learning environments. This model also produced good fit indices $\left(\chi^{2}(918)=1515.023, p\left(\chi^{2}\right)<.001\right.$, CFI $=.94$, TLI $=.94$, $\operatorname{RMSEA}(90 \% \mathrm{CI})=.05[.04, .05], \mathrm{SRMR}=.09)$.

Last, a model with more restrictions (model 3) was tested, which additionally placed equality constraints on all the direct effects and residual covariance coefficients across all four groups, implying the non-existence of group differences, both in terms of the learning environment and the age of the students. This model produced a good fit as well: $\chi 2(928)=$ $1534.198, p\left(\chi^{2}\right)<.001, \mathrm{CFI}=.94, \mathrm{TLI}=.94, \mathrm{RMSEA}(90 \% \mathrm{CI})=.05[.04, .05], \mathrm{SRMR}=.10$

Finally, the models were compared in a step-wise procedure. The comparisons of model 1 and model $2\left(\Delta \chi^{2}=32.34, \Delta \mathrm{df}=20 ; p<.05 ; \Delta \mathrm{CFI}=.00 ; \Delta \mathrm{TLI}=.00 ; \Delta \mathrm{RMSEA}\right.$ $=.00 ; \Delta \mathrm{SRMR}=.01)$, and the comparisons of model 2 and model $3\left(\Delta \chi^{2}=19.06, \Delta \mathrm{df}=10 ; p\right.$ $<.05 ; \Delta \mathrm{CFI}=.00 ; \Delta \mathrm{TLI}=.00 ; \Delta \mathrm{RMSEA}=.00 ; \Delta \mathrm{SRMR}=.01)$ indicated a slight, but significant decreases in model fit when introducing the equality constraints. Consequently, significant differences in the patterns between the variables of interest among the four groups were assumed based on the final least restrictive model (model 1).

\section{Table 3}

Results of the Alternative Model 


\section{COMPETENCE-SUPPORT IN DIFFERENT LEARNING ENVIRONMENTS}

\begin{tabular}{|c|c|c|c|c|c|c|c|c|c|c|c|c|}
\hline \multirow[b]{2}{*}{ Predictors } & \multicolumn{4}{|c|}{ focus_t2 } & \multicolumn{4}{|c|}{ persistence_t2 } & \multicolumn{4}{|c|}{ accuracy_t2 } \\
\hline & $B$ & $\beta$ & $S E$ & $p$ & $B$ & $\beta$ & $S E$ & $p$ & $B$ & $\beta$ & $S E$ & $p$ \\
\hline \multicolumn{13}{|l|}{$C B L 7 / 8$} \\
\hline $\begin{array}{l}\text { academic self- } \\
\text { concept_t1 }\end{array}$ & 0.34 & 0.35 & 0.05 & $<.001$ & 0.35 & 0.37 & 0.05 & $<.001$ & 0.29 & 0.26 & 0.06 & $<.001$ \\
\hline $\begin{array}{l}\text { perceived } \\
\text { competence } \\
\text { support_t1 }\end{array}$ & 0.33 & 0.35 & 0.05 & $<.001$ & 0.28 & 0.30 & 0.04 & $<.001$ & 0.37 & 0.32 & 0.06 & $<.001$ \\
\hline \multicolumn{13}{|l|}{$C B L 9 / 10$} \\
\hline $\begin{array}{l}\text { academic self- } \\
\text { concept_t1 }\end{array}$ & 0.29 & 0.33 & 0.12 & $<.05$ & 0.30 & 0.32 & 0.12 & $<.05$ & 0.33 & 0.27 & 0.10 & $<.01$ \\
\hline $\begin{array}{l}\text { perceived } \\
\text { competence } \\
\text { support_t1 }\end{array}$ & 0.21 & 0.27 & 0.12 & $=.09$ & 0.19 & 0.23 & 0.10 & $=.06$ & 0.28 & 0.27 & 0.08 & $<.001$ \\
\hline \multicolumn{13}{|l|}{$T D L 7 / 8$} \\
\hline $\begin{array}{l}\text { academic self- } \\
\text { concept_t1 }\end{array}$ & 0.44 & 0.47 & 0.08 & $<.001$ & 0.38 & 0.36 & 0.12 & $<.01$ & 0.14 & 0.16 & 0.09 & $=.10$ \\
\hline $\begin{array}{l}\text { perceived } \\
\text { competence } \\
\text { support_t1 }\end{array}$ & 0.21 & 0.22 & 0.09 & $<.05$ & 0.24 & 0.24 & 0.10 & $<.05$ & .017 & 0.18 & 0.08 & $<.05$ \\
\hline \multicolumn{13}{|l|}{$T D L 9 / 10$} \\
\hline $\begin{array}{l}\text { academic self- } \\
\text { concept_t1 }\end{array}$ & 0.21 & 0.21 & 0.19 & $=.26$ & 0.35 & 0.32 & 0.13 & $<.01$ & 0.08 & 0.06 & 0.16 & $=.63$ \\
\hline $\begin{array}{l}\text { perceived } \\
\text { competence } \\
\text { support_t1 }\end{array}$ & 0.10 & 0.12 & 0.08 & $=.24$ & 0.05 & 0.05 & 0.11 & $=.68$ & 0.10 & 0.11 & 0.11 & $=.35$ \\
\hline
\end{tabular}

Note. Self-concept_t $1=$ academic self-concept time 1 , competence support_t $1=$ competence

support time 1, focus_t $2=$ focus time 2 , accuracy_t $2=$ accuracy time 2 , persistence_t $2=$ persistence time 2; significant paths are displayed in bold at $p<.05$ level. 